\title{
RELACIONES PATRIMONIALES DE LAS PAREJAS TRANSFRONTERIZAS DEL MISMO SEXO EN LA UE ${ }^{1 *}$
}

\section{Filip Dougan}

Ayudante doctor en la Facultad de Derecho de la Universidad de Ljubljana E-mail: filip.dougan@pf.uni-lj.si

\begin{abstract}
RESUMEN: Este trabajo tratará de presentar algunos de los retos a los que se enfrentan las parejas transfronterizas en lo que respecta a sus relaciones patrimoniales en virtud del Reglamento. También explorará las posibilidades que pueden mitigar su incierta situación jurídica, identificará las cuestiones que siguen abiertas y propondrá soluciones para garantizar a las parejas transfronterizas del mismo sexo un mayor nivel de previsibilidad jurídica.

Palabras clave: parejas transfronterizas, mismo sexo, ámbito material, elección del foro.

ABSTRACT: This paper will attempt to present some of the challenges that cross-border same-sex couples face concerning their property relations under the Twin Regulations. It will also explore the possibilities which may mitigate their uncertain legal position, identify questions that remain open and propose solutions in order to ensure the same-sex cross-border couples a greater level of legal predictability.
\end{abstract}

Keywords: cross-border couples, same-sex couples, material scope of application, prorogatio fori, choice of law.

SUMARIO: I. INTRODUCCIÓN. II. LAS PAREJAS DEL MISMO SEXO Y SU EVOLUCIÓN HASTA LA ADOPCIÓN DE LOS reglamentos gemelos. III. Ámbito de aplicación material y personal. 3.1. Uniones registradas. 3.2. La noción de matrimonio y la caracterización de los matrimonios del mismo sexo. IV. JURISDicCión ALTERNATIVA. V. LA aUtonomía de los PaRtidos: ¿UNa POSIble SOLUCión a La INCERTIDUMbRe? 5.1. Acuerdo de elección de foro. 5.2. Acuerdos de elección de ley. VI. REConocimiento y EJECUCIÓN. VII. OBSERVACIONES FINALES.

$1{ }^{*}$ Traducido por Ana María Pérez Vallejo, Profesora Titular de Derecho civil y Nuria Martínez Sánchez, Doctora en el departamento de Derecho civil de la Universidad de Almería. 


\section{INTRODUCCIÓN}

A lo largo de las tres últimas décadas se han logrado importantes avances en la concesión y protección de los derechos de las parejas del mismo sexo en Europa. A partir de hitos como la aprobación de la Ley danesa de parejas registradas en 1989, que permitió por primera vez la formalización de las parejas del mismo sexo, ${ }^{2}$ y la modificación del artículo 30 del Código Civil holandés, que en 2001 abrió por primera vez el matrimonio a las parejas del mismo sexo, ${ }^{3}$ cada vez más países de todo el mundo y, en particular, de la Unión Europea (en adelante, la UE) empezaron a introducir legislación que reconoce legalmente las relaciones entre personas del mismo sexo y, en consecuencia, los derechos (incluidos los patrimoniales) derivados de dichas relaciones. Por otro lado, se observa que estos avances también se enfrentaron a una creciente preocupación en parte de los Estados miembros que consideran que conceder más derechos a las parejas del mismo sexo o incluso permitirles casarse podría socavar los "valores tradicionales" relativos a las relaciones familiares y de pareja. Letonia, Hungría, Croacia y Eslovaquia llegaron a promulgar una prohibición constitucional de los matrimonios entre personas del mismo sexo. ${ }^{4}$

Estas opiniones divergentes sobre el reconocimiento legal de las parejas del mismo sexo y sus derechos se traducen en notables diferencias en los enfoques nacionales del derecho de familia de los Estados miembros de la UE. Esto es evidente no sólo cuando se trata del reconocimiento de las relaciones entre personas del mismo sexo, sino también en lo que respecta a la regulación de sus derechos patrimoniales. A este respecto, los Estados miembros de la UE podrían dividirse a grandes rasgos en tres grupos. El primer grupo, formado por trece Estados miembros, ${ }^{5}$ reconoce el matrimonio entre personas del mismo sexo; el segundo grupo, formado por ocho Estados miembros, ${ }^{6}$ no permite que las parejas del mismo sexo se casen, pero sí que formen una unión registrada ${ }^{7}$; el tercer grupo está formado por seis Estados miembros ${ }^{8}$ en los que no se permite ni el matrimonio ni la unión registrada para las parejas del mismo sexo. ${ }^{9}$ Dependiendo del grupo al que pertenezca el país, su posición con respecto a las parejas del mismo sexo difiere. Mientras que el primer grupo concede los derechos más amplios a estas parejas, su situación en el tercer grupo (países que se niegan a reconocer legalmente a las parejas del mismo sexo) están mucho menos protegida.

2 I. LUND-ANDERSEN, 'Northern Europe: Same-sex Relationships and Family Law' in K. BOELE-WOELKI and A. FUCHS (eds), Same-sex Relationships and Beyond, Intersentia, Cambridge, 2017, p. 5.

3 F. W. J. M. SCHOLS and T. F. H. REIJNEN, 'The Netherlands' in L. RUGGERI, I. KUNDA, S. WINKLER (eds), Family Property and Succession in EU Member States: National Reports on the Collected Data, University of Rijeka, Faculty of Law, Rijeka, 2019, p. 487.

4 S. KRALJIĆ, 'Same-sex partnerships in Eastern Europe' in K. BOELE-WOELKI and A. FUCHS (eds), Same-sex Relationships and Beyond, Intersentia, Cambridge, 2017, pp. 61-62.

5 Austria (2019), Bélgica (2003), Dinamarca (2012), Finlandia (2017), Francia (2013), Alemania (2017), Irlanda (2015), Luxemburgo (2015), Malta (2017), Países Bajos (2001), Portugal (2010), España (2005) y Suecia (2009).

6 Croacia (2014), Chipre (2015), Chequia (2006), Estonia (2016), Grecia (2015), Hungría (2009), Italia (2016) y Eslovenia (2006).

7 Cabe señalar que las legislaciones nacionales de estos Estados miembros suelen referirse a estas parejas registradas registradas con diversos términos, como unión civil, pareja de hecho, pareja de hecho, acuerdo de cohabitación, convivencia, etc. Sin embargo, a efectos de este capítulo, se ha utilizado intencionadamente el término unión registrada de forma intencionada, ya que refleja la terminología del Reglamento sobre las consecuencias patrimoniales de las uniones registradas. También hay que tener en cuenta que los derechos que se derivan de estas relaciones varían significativamente entre estos Estados miembros.

8 Bulgaria, Letonia, Lituania, Polonia, Eslovaquia y Rumanía.

9 Véase inter alia: L. RUGGERI, I. KUNDA, S. WINKLER (eds), Family Property and Succession in EU Member States: National Reports on the Collected Data, University of Rijeka, Faculty of Law, Rijeka, 2019. 
Las enormes diferencias en las legislaciones nacionales plantean inevitablemente grandes retos para la armonización del Derecho internacional privado entre los Estados miembros. Esto también se puso de manifiesto en el proceso de adopción del Reglamento sobre el régimen económico matrimonial y el Reglamento sobre los efectos patrimoniales de las uniones registradas (en adelante, conjuntamente, los Reglamentos gemelos). Aunque uno de los principales objetivos de los Reglamentos gemelos era lograr un mayor nivel de seguridad jurídica para las parejas transfronterizas en lo que respecta a sus relaciones patrimoniales, ${ }^{10}$ las parejas transfronterizas del mismo sexo siguen enfrentándose a una gran imprevisibilidad. Se observa que a menudo se ha sacrificado su seguridad jurídica para lograr la unanimidad y atender las preocupaciones de los Estados miembros, que temen que la adopción del Reglamento les obligue a reconocer las uniones del mismo sexo desconocidas en sus sistemas jurídicos. ${ }^{11}$ Por lo tanto, este capítulo tratará de presentar algunos de los retos a los que se enfrentan estas parejas en lo que respecta a sus relaciones patrimoniales en virtud del Reglamento. También explorará las posibilidades que pueden mitigar su incierta situación jurídica, identificará las cuestiones que siguen abiertas y propondrá soluciones para garantizar a las parejas transfronterizas del mismo sexo un mayor nivel de previsibilidad jurídica.

\section{LAS PAREJAS DEL MISMO SEXO Y SU EVOLUCIÓN HASTA LA ADOPCIÓN DE LOS REGLAMENTOS GEMELOS}

Han pasado más de 17 años desde la idea inicial de un instrumento europeo que regule los aspectos de Derecho internacional privado de los regímenes matrimoniales y la adopción de los Reglamentos gemelos. El proceso legislativo demuestra que este largo período puede atribuirse en parte a las cuestiones relativas al reconocimiento de las relaciones entre personas del mismo sexo. ${ }^{12} \mathrm{Al}$ mismo tiempo, un examen más detallado de los travaux préparatoires puede permitir comprender mejor las razones del tratamiento de las parejas transfronterizas del mismo sexo en el marco del Reglamento sobre las parejas gemelas y los retos a los que se enfrentan.

La necesidad de armonizar el Derecho internacional privado en el ámbito de las relaciones patrimoniales de las parejas se destacó por primera vez en el Plan de Acción de Viena de $1998^{13}$ y el Programa de medidas para la aplicación del principio de reconocimiento mutuo de las resoluciones judiciales en materia civil y mercantil, ${ }^{14}$ adoptado en el año 2000. Mientras que el primero se refería únicamente a los regímenes matrimoniales, el segundo proponía también la introducción de instrumentos jurídicos relativos a las "consecuencias patrimoniales de la separación de las parejas no casadas". Sin embargo,

10 Considerando 15 de los Reglamentos gemelos.

11 A. WYSOCKA-BAR, 'Enhanced Cooperation in Property Matters in the EU and Non-Participating Member States' (2019) 20 ERA Forum 187, 192.

12 Para un análisis más detallado del proceso que condujo a la adopción de los Reglamentos gemelos y los desafíos que se han planteado, véase el capítulo 2 de este volumen.

13 Plan de Acción del Consejo y la Comisión de 3 de diciembre de 1998 sobre la mejor manera de aplicar las disposiciones del el Tratado de Amsterdam sobre la creación de un espacio de libertad, seguridad y justicia [1999] DO C $19 / 1$.

14 Proyecto de programa de medidas para la aplicación del principio de reconocimiento mutuo de las decisiones en en materia civil y mercantil [2001] DO C 12/1. 
ninguna de ellas hacía referencia a las parejas del mismo sexo. Esto cambió en 2006, cuando la Comisión Europea publicó un Libro Verde sobre las cuestiones de los regímenes matrimoniales ${ }^{15}$ y lanzó una "amplia consulta" al respecto. A pesar de omitir una mención explícita a las parejas del mismo sexo, el Libro Verde señalaba que los Estados miembros prevén cada vez más uniones registradas, por lo que la Comisión Europea amplió la consulta también a las consecuencias patrimoniales de dichas uniones.

Cuando la Comisión Europea presentó las propuestas de los Reglamentos geme$\operatorname{los}^{16}$-que tratan por separado de los regímenes matrimoniales y de las consecuencias patrimoniales de las parejas registradas- quedó claro rápidamente que alcanzar un consenso sería una tarea dificil. Hay que tener en cuenta que la UE trató de ejercer su competencia basándose en el apartado 3 del artículo 81 del Tratado de Funcionamiento de la Unión Europea (en adelante, TFUE), ${ }^{17}$ que exige una decisión unánime de los Estados miembros en el Consejo. Al presentar las propuestas, varios Estados miembros de Europa del Este expresaron su preocupación por el hecho de que la adopción de los Reglamentos gemelos obligará a sus tribunales a reconocer las consecuencias patrimoniales derivadas de los matrimonios y uniones registradas entre personas del mismo sexo, lo que, en consecuencia, extenderá los efectos jurídicos de dichas relaciones a su territorio. ${ }^{18}$ Durante la reunión del Consejo en diciembre de 2015, finalmente quedó claro que no se podía alcanzar un consenso debido a la oposición de Hungría y Polonia. ${ }^{19}$ Por ello, varios Estados miembros expresaron su deseo de establecer una cooperación reforzada en este ámbito. Su propuesta fue autorizada por el Consejo ${ }^{20}$ y los Reglamentos gemelos se adoptaron el 24 de junio de 2016. En consecuencia, los Reglamentos gemelos solo son aplicables en 18 Estados miembros participantes, ${ }^{21}$ mientras que el resto de los Estados miembros siguen aplicando sus normas nacionales de Derecho internacional privado.

\section{III. ÁMBITO DE APLICACIÓN MATERIAL Y PERSONAL}

La cuestión central, que puede influir significativamente en las parejas transfronterizas del mismo sexo, es la de si el tribunal competente puede o no aplicar el Reglamento de

15 Libro Verde sobre los conflictos de leyes en materia de regímenes matrimoniales, incluida la cuestión de la competencia y el reconocimiento mutuo, COM (2006) 400 final.

16 Propuesta de Reglamento del Consejo relativo a la competencia, la ley aplicable, el reconocimiento y la ejecución de decisiones en materia de regímenes matrimoniales, COM/2011/126 final y Propuesta de Reglamento del Consejo relativo a la competencia, la ley aplicable, el reconocimiento y la ejecución de las resoluciones relativas a los efectos patrimoniales de las uniones registradas, COM/2011/127 final.

17 Versión consolidada del Tratado de Funcionamiento de la Unión Europea [2012] DO C 326/47.

18 A. WYSOCKA-BAR, above n. 9, p. 187.

19 Resultado de la reunión del Consejo, Bruselas, 3 y 4 de diciembre de $2015<\underline{\text { https://www.consilium.europa.eu/ }}$ media/23027/st14937en15 v5.pdf> accessed 27.4.2021; A. MARINI, 'Poland and Hungary Blocked EU' [2015] Euinside $<$ http://www.euinside.eu/en/news/poland-and-hungary-blocked-eu-on-matrimonial-property-regimes $>$ consultado el 27.4.2021.

20 Decisión (UE) 2016/954 del Consejo, de 9 de junio de 2016, por la que se autoriza una cooperación reforzada en materia de competencia, la ley aplicable y el reconocimiento y la ejecución de resoluciones sobre los regímenes patrimoniales de las parejas internacionales, abarcando tanto las cuestiones de los regímenes matrimoniales como las consecuencias patrimoniales de las uniones registradas [2016] DO L 159/16.

21 Alemania, Austria, Bélgica, Bulgaria, Croacia, Chipre, República Checa, Finlandia, Francia, Grecia, Italia, Luxemburgo, Malta, Países Bajos, Portugal, Eslovenia, España y Suecia. 
Gemelos al decidir sobre sus relaciones patrimoniales y, en caso afirmativo, cuál de los dos Reglamentos se aplicará.

Si bien el ámbito de aplicación territorial y temporal, así como el contenido de los Reglamentos gemelos son muy similares (véase el capítulo 3 de este volumen), la distinción más importante se produce en relación con su ámbito de aplicación material y personal. De conformidad con el artículo 1, el Reglamento sobre el régimen económico matrimonial se aplica a los "regímenes económicos matrimoniales" y el Reglamento sobre las consecuencias patrimoniales de las uniones registradas se aplica a las "consecuencias patrimoniales de las uniones registradas". Ambas expresiones se definen respectivamente en el artículo 3 de cada reglamento. La primera representa "el conjunto de normas relativas a las relaciones patrimoniales de los cónyuges entre sí y en sus relaciones con terceros, como consecuencia del matrimonio o de su disolución"; y la segunda establece "el conjunto de normas relativas a las relaciones patrimoniales de los convivientes, entre sí y en sus relaciones con terceros, como consecuencia de la relación jurídica creada por las inscripciones de la pareja de hecho o de su disolución”.

A primera vista, parece que estas definiciones trazan una clara línea entre su ámbito de aplicación. El Reglamento de régimen económico matrimonial se aplicará a las relaciones patrimoniales de los cónyuges y el Reglamento sobre las consecuencias patrimoniales de las uniones registradas se aplicará a las relaciones patrimoniales de las parejas registradas. Sin embargo, un examen más detallado revela que esta distinción sigue siendo relativamente poco clara cuando se trata de parejas del mismo sexo. Para abordar estas cuestiones, es necesario examinar más detenidamente las nociones de "matrimonio" y "pareja registrada".

\subsection{Uniones registradas}

El Reglamento sobre los efectos patrimoniales de las uniones registradas incluye una definición autónoma de unión registrada en el artículo 3, apartado 1, letra a). Define la unión registrada como un "régimen que regula la vida en común de dos personas y que está previsto en la ley, cuyo registro es obligatorio en virtud de dicha ley y que cumple las formalidades legales exigidas por ésta para su creación”. De hecho, es la primera vez que un instrumento de la UE en el ámbito del Derecho internacional privado ofrece una definición de pareja registrada. ${ }^{22}$ No obstante, cabe señalar que dicha definición se estableció únicamente a efectos del Reglamento sobre las consecuencias patrimoniales de las uniones registradas y que el contenido real del concepto de unión registrada sigue definiéndose en las legislaciones nacionales de los Estados miembros (considerando 17 del Reglamento sobre las consecuencias patrimoniales de las uniones registradas).

Del texto de la letra a) del apartado 1 del artículo 3 pueden extraerse tres conclusiones principales. En primer lugar, la definición omite cualquier referencia al sexo de los miembros de la pareja como condición para que se le aplique el concepto de pareja registrada. Por lo tanto, el ámbito de aplicación personal se extiende no sólo a las parejas

22 C. RUDOLF, European Property Regimes Regulations - Choice of Law and the Applicable Law in the Abscence of Choice by the parties (2019) 11 LeXonomica 127, p. 133. 
registradas de distinto sexo, sino también a las parejas registradas del mismo sexo. ${ }^{23}$ Esta conclusión se ve corroborada por los trabajos preparatorios del Reglamento sobre las consecuencias patrimoniales de las uniones registradas, donde se observa que, de hecho, uno de los objetivos de su adopción era abordar las consecuencias patrimoniales de las uniones registradas, abiertas a las parejas del mismo sexo. ${ }^{24}$ En segundo lugar, la definición estipula claramente que el registro de una pareja es obligatorio para entrar en el ámbito de aplicación del Reglamento sobre las consecuencias patrimoniales de las uniones registradas. El considerando 16 explica además que hay que distinguir entre las parejas cuya unión está sancionada institucionalmente por el registro de su pareja ante una autoridad pública y las parejas en convivencia de hecho. Por lo tanto, de facto las uniones de hecho, tanto del mismo sexo como del sexo opuesto, quedan claramente fuera del ámbito de aplicación. ${ }^{25}$ Así, sus relaciones patrimoniales se regirán por las normas internas de Derecho internacional privado. ${ }^{26}$ Por último, puede observarse, como han señalado algunos comentaristas del Reglamento sobre las parejas de hecho, que, de acuerdo con la definición, los cónyuges no entran claramente en el ámbito de aplicación del Reglamento sobre las consecuencias patrimoniales de las uniones registradas. ${ }^{27}$ Aunque esta conclusión se desprende de la redacción y la estructura de ambos Reglamentos, en algunos Estados miembros los cónyuges del mismo sexo podrían ser tratados como parejas registradas, como se explicará a continuación.

\subsection{La noción de matrimonio y la caracterización de los matrimonios del mismo sexo}

A diferencia del Reglamento sobre las consecuencias patrimoniales de las uniones registradas, el Reglamento sobre el régimen económico matrimonial no define el matrimonio como base necesaria para la existencia de regímenes económicos matrimoniales. En su lugar, se arroja algo de luz sobre la cuestión en el considerando 17, que establece que el matrimonio se define por el derecho nacional de los Estados miembros. De este modo, se evitó una definición autónoma del matrimonio a nivel europeo en el Reglamento sobre el régimen económico matrimonial. Hay que señalar que este enfoque se adoptó intencionadamente debido a las opiniones divergentes de los Estados miembros respecto a los matrimonios entre personas del mismo sexo. ${ }^{28}$ Se pretendía que, al omitir una definición autónoma del matrimonio, la unanimidad entre los Estados miembros, en particular los que limitan el matrimonio a los cónyuges de distinto sexo, fuera más fácil de conseguir. Al mismo tiempo, esto también permite a los Estados miembros no participantes, que no permiten los matrimonios entre personas del mismo sexo, unirse a la cooperación reforzada más adelante. ${ }^{29}$

23 R. HAUSMANN, Internationales und Europäisches Familienrecht, C. H. Bech, München 2018, p. 980; M. ANDRAE, Internationales Familienrecht, Nomos, Baden-Baden, 2019, p. 243; A. RODRIGUEZ BENOT, 'Article 3' in P. FRANZINA and I. VIARENGO, The EU Regulations on the Property Regimes of International Couples: A Commentary, Edwad Elgar Publishing, Cheltenham, 2020, p. 38.

24 Véase inter alia: Green paper, $\operatorname{COM}(2006) 400$ final, p. 10.

25 Para las relaciones patrimoniales de las parejas de hecho transfronterizas, véase el capítulo 10 de este volumen.

26 En el artículo 41 de la Ley eslovena de Derecho Internacional Privado y de Procedimiento y en el artículo 40 de la Ley croata de Derecho Internacional Privado se encuentran disposiciones especiales sobre la unión de hecho. esloveno y en el artículo 40 de la Ley de Derecho Internacional Privado croata.

27 RODRIGUEZ BENOT, above n. 22, p. 35; M. ANDRAE, above n. 22, p. 241.

28 A. DUTTA, 'Beyond Husband and Wife - New Couple Regimes and the European Property Regulations' (2017/2018) 19 Yearbook of Private International Law 145, 148.

29 M. ANDRAE, above n. 22, p. 243. 
Aunque las razones de este enfoque "pragmático" pueden ser comprensibles teniendo en cuenta las dificultades que aparecieron en el proceso de adopción de los Reglamentos gemelos, la falta de una definición autónoma obstaculiza gravemente la seguridad jurídica y la certidumbre legal de las parejas del mismo sexo. La referencia al derecho nacional de los Estados miembros en el considerando 17 significa que cada Estado miembro participante puede interpretar la noción de matrimonio de forma diferente. En consecuencia, la delimitación del ámbito de aplicación personal de los Reglamentos gemelos no se regula de forma autónoma. ${ }^{30}$ En la práctica, esto se traduce en el hecho de que algunos Estados miembros aplicarán el Reglamento sobre el régimen económico matrimonial al decidir sobre las relaciones patrimoniales de los cónyuges del mismo sexo, mientras que los demás podrían aplicar en su lugar el Reglamento sobre las consecuencias patrimoniales de las uniones registradas.

La incertidumbre también proviene de la vaguedad del considerando 17. No está claro a qué legislación nacional de los Estados miembros apunta el considerando 17. Hay varias interpretaciones posibles. La opinión predominante en la literatura científica parece ser que la referencia al derecho nacional significa el derecho del Estado cuyos tribunales conocen del asunto (lex fori). ${ }^{31}$ Sin embargo, incluso con esta interpretación, la cuestión sigue siendo si el tribunal competente debe calificar el matrimonio entre personas del mismo sexo de acuerdo con su derecho sustantivo o de acuerdo con sus normas de conflicto de leyes. ${ }^{32}$

La situación jurídica de las parejas del mismo sexo es más segura en los 11 Estados miembros participantes, donde se permite a estas parejas contraer matrimonio. ${ }^{33}$ Está ampliamente aceptado que estos estados deben caracterizar el matrimonio entre personas del mismo sexo simplemente como matrimonio y aplicar el Reglamento de regímenes económicos matrimoniales. ${ }^{34}$ La caracterización de acuerdo con la lex fori no debería representar problemas particulares para la aplicación de dicho Reglamento, ya que estos Estados miembros equiparan los matrimonios del mismo sexo con los matrimonios tradicionales entre los cónyuges del sexo opuesto.

En cambio, la situación jurídica es menos segura cuando la competencia para decidir sobre el régimen económico matrimonial de los cónyuges del mismo sexo corresponde a los tribunales de siete Estados miembros participantes cuya legislación no contempla el matrimonio entre personas del mismo sexo. ${ }^{35} \mathrm{Si}$ la referencia al derecho nacional en el considerando 17 se interpreta como una referencia al derecho sustantivo (nacional) del Estado miembro a cuyos tribunales se acudió, el tribunal competente podría tener que concluir que los cónyuges del mismo sexo no entran en el ámbito de aplicación del Reglamento sobre el régimen económico matrimonial. Si el tribunal llega a tal conclusión, se suele proponer que se valore el matrimonio entre personas del mismo sexo como si fuera

30 R. HAUSMANN, above n. 22, p. 980.

31 A. DUTTA, above n. 27, p. 149; I. KUNDA 'Novi međunarodnoprivatnopravni okvir imovine bračnih i registriranih partnera u Europskoj uniji: polje primjene i nadležnost' (2019) 3 Hrvatska pravna revija 27, 29.

32 C. RUDOLF, above n. 21, pp. 134-135; S. MARINO, 'Strengthening the European Civil Judicial Cooperation: the patrimonial effects of family relationships' (2017) 9 Cuadernos de Derecho Transnacional 265, p. 267.

33 Alemania, Austria, Bélgica, España, Finlandia, Francia, Luxemburgo, Malta, Países Bajos, Portugal y Suecia.

34 R. HAUSMANN, above n. 22, p. 980; S. MARINO, above n. 31, p. 268.

35 Bulgaria, Croacia, Chipre, República Checa, Grecia, Italia y Eslovenia. 
una pareja registrada y aplique, en consecuencia, el Reglamento sobre las consecuencias patrimoniales de las parejas registradas. ${ }^{36}$

Sin embargo, como se ha mencionado anteriormente, es posible otra interpretación. En lugar de calificar el matrimonio entre personas del mismo sexo de acuerdo con el derecho sustantivo del Estado miembro a cuyos tribunales se recurrió, el tribunal competente podría remitirse también a sus normas nacionales de conflicto de leyes. Esta opción conduce de nuevo a varias posibilidades. El tribunal podría calificar el matrimonio entre personas del mismo sexo de acuerdo con la lex causae aplicable en virtud de las normas de conflicto nacionales o podría examinar si la relación entre la pareja del mismo sexo puede ser reconocida de cualquier forma. ${ }^{37}$ Según la literatura científica, esta solución es preferible al enfoque en el que el tribunal competente se basa únicamente en la definición de su derecho sustantivo. ${ }^{38} \mathrm{Al}$ enfocar la caracterización de los matrimonios del mismo sexo de esta manera, la aplicación del Reglamento de régimen económico matrimonial no queda totalmente excluida en los Estados miembros que no regulan dichos matrimonios en su derecho sustantivo, como se demostrará más adelante. Por lo tanto, este enfoque también puede ser preferible para los cónyuges del mismo sexo, ya que deja la posibilidad de que su matrimonio no sea "degradado".

No obstante, incluso con esta interpretación del considerando 17, no se puede evitar por completo la "degradación" del matrimonio entre personas del mismo sexo. El Derecho internacional privado interno de algunos Estados miembros participantes se anticipó a los problemas mencionados con la caracterización de los matrimonios del mismo sexo e intentó resolver esta cuestión por adelantado. En Italia, el art. 32-bis de la Ley $n^{\circ}$ 218 de 31 de mayo de 1995 (Legge 31 maggio 1995, n. 218) ${ }^{39}$ estipula que el matrimonio contraído en el extranjero por ciudadanos italianos con una persona del mismo sexo produce los efectos de una unión registrada (unione civile), tal como se regula en la legislación italiana. Esta disposición se incluyó para evitar que los ciudadanos italianos contrajeran matrimonio en el extranjero con personas del mismo sexo, eludiendo así la legislación italiana, que sólo contempla las parejas registradas del mismo sexo. ${ }^{40}$ Según la decisión del Tribunal Supremo italiano, ${ }^{41}$ esta "degradación" se produce no sólo en las situaciones en las que el matrimonio fue celebrado en el extranjero por dos ciudadanos italianos, sino también en los casos de matrimonios mixtos del mismo sexo entre un ciudadano italiano y un extranjero. ${ }^{42}$ Esto indica que al tratar las relaciones patrimoniales de los cónyuges transfronterizos del mismo sexo cuando al menos uno de los cónyuges es italiano, los tribunales de Italia tendrán que aplicar el Reglamento sobre las consecuencias patrimoniales de las uniones registradas.

36 Véase: R. HAUSMANN, above n. 22, p. 980; S. MARINO, above n. 31, p. 268; A. BONOMI, 'Fragen des Allgemeinen Teils: Qualifikation, Vorfrage, Renvoi und ordre public' in A. DUTTA and J. WEBER (eds), Die Europäischen Güterrechtsverordnungen, C. H. Beck, Munich 2017, pp. 133-134.

37 A. DUTTA, above n. 27, p. 152.

38 A. BONOMI, above n. 35, p. 132; A. DUTTA, above n. 27, p. 152-153.

39 GU n.128 del 03-06-1995 - Suppl. Ordinario n. 68.

40 M. WINKLER, 'A Case with peculiarities: Mixed Same-Sex Marriages Before the Supreme Court' (2018) 4 The Italian Law Journal 273, p. 281.

41 Corte di Cassazione n 11696/2018 of 14 May 2018.

42 Véase también M. M. WINKLER, above n. 39, pp. 284 - 286. 
En Croacia se observa un enfoque aún más restrictivo. El artículo 32(2) de la Ley de Derecho Internacional Privado de Croacia (Zakon o međunardonom privatnom pravu, ZMPP) ${ }^{43}$ estipula que los matrimonios entre personas del mismo sexo celebrados en el extranjero se reconocerán como uniones civiles (con la condición de que el matrimonio se haya celebrado de acuerdo con la legislación del Estado en el que se haya celebrado). A diferencia de la situación en Italia, esta disposición lleva a la conclusión de que todos los matrimonios entre personas del mismo sexo (no sólo los que pueden considerarse que eluden la legislación nacional) serán "rebajados" y tratados como uniones registradas.

Es importante señalar que esta cuestión está lejos de ser únicamente teórica. La "degradación" del matrimonio entre personas del mismo sexo puede tener importantes implicaciones en el régimen patrimonial entre los cónyuges. Para demostrar estas consecuencias prácticas, a continuación se ofrece un ejemplo.

Peter (ciudadano alemán) y Michael (ciudadano danés) contrajeron matrimonio en Alemania el 1 de febrero de 2019. En el momento de contraer matrimonio, ambos trabajaban en Austria, donde tenían su residencia habitual en ese momento y después de casarse. El 1 de febrero de 2020, los cónyuges se trasladaron a la Alternativa 1: Alemania, a la Alternativa 2: Croacia; a la Alternativa 3: Eslovenia, donde los tribunales acudieron el 1 de junio de 2021 para decidir sobre su patrimonio matrimonial (no se inició el procedimiento de divorcio). Los cónyuges nunca celebraron un acuerdo de elección de tribunal o de elección de ley. ${ }^{44}$

Para demostrar cómo el traslado a un país diferente afecta al resultado del caso, el ejemplo ofrece tres alternativas. Sin embargo, cabe señalar en primer lugar que en las tres alternativas (e independientemente de cuál de los dos Reglamentos sea aplicable) la competencia internacional se regirá por el mismo factor de vinculación. Teniendo en cuenta que el procedimiento sobre los bienes matrimoniales no se inició en relación con la solicitud de divorcio, separación legal o nulidad del matrimonio, ni en relación con el procedimiento de sucesión después de un cónyuge, la competencia corresponderá a los tribunales del Estado miembro en cuyo territorio los cónyuges/parejas tengan su residencia habitual en el momento en que se acuda al tribunal (artículo 6(1)(1) del Reglamento sobre los bienes matrimoniales y del Reglamento sobre las consecuencias patrimoniales de las uniones registradas). ${ }^{45}$ Así, dependiendo de la alternativa, la jurisdicción en el presente caso recaerá en los tribunales de Alemania, Croacia o Eslovenia.

En la alternativa 1, los tribunales alemanes aplicarán el Reglamento de régimen económico matrimonial (Alemania participa en la cooperación reforzada) para decidir sobre las relaciones patrimoniales de Peter y Michael. A primera vista, se puede llegar a la conclusión

43 NN 101/17.

44 Dado que el matrimonio entre Peter y Michael se celebró el 1 de febrero de 2019 y los tribunales acudieron a él el 1 de junio de 2021, los Reglamentos gemelos pueden aplicarse en su totalidad. No obstante, cabe señalar que, de conformidad con el artículo 69, apartado 3, el capítulo III, que contiene las disposiciones de conflicto de leyes, solo es aplicable a los cónyuges que contraigan matrimonio o que especifiquen el régimen económico matrimonial aplicable a partir del 29 de enero de 2019. Si los cónyuges hubieran celebrado su matrimonio antes de esa fecha, los tribunales tendrían que aplicar las normas de conflicto interno. Véase el capítulo 3 de este volumen relativo al ámbito temporal de aplicación de los Reglamentos gemelos.

45 Véase el capítulo 4 de este volumen en relación con la jurisdicción internacional en virtud de los Reglamentos gemelos. 
de que el Reglamento de régimen económico matrimonial es aplicable al observar que el derecho sustantivo alemán abrió la institución del matrimonio a los cónyuges del mismo sexo. ${ }^{46}$ Sin embargo, si se sigue el argumento de que la referencia al derecho nacional en el considerando 17 también incluye el derecho internacional privado interno, las disposiciones de la Ley de introducción al código civil alemán (Einführungsgesetz zum Bürgerlichen Gesetzbuche, EGBGB $)^{47}$ también debe ser examinada. De sus disposiciones se desprende que el legislador alemán se anticipó a los problemas de caracterización del matrimonio entre personas del mismo sexo. Así, el artículo 17.b(4) del EGBGB estipula explícitamente que las consecuencias patrimoniales del matrimonio entre cónyuges del mismo sexo (o cónyuges en los que al menos uno de ellos no se identifica con el sexo femenino o masculino) deben determinarse de acuerdo con la ley aplicable en virtud del Reglamento de los regímenes económico matrimoniales. ${ }^{48}$ Por lo tanto, la ley aplicable en el presente caso se determinará de conformidad con el artículo 26, apartado 1, letra a), de dicho Reglamento. Será la ley austriaca, ya que es la ley del Estado de la primera residencia habitual común de los cónyuges tras la celebración del matrimonio. Esta conclusión probablemente satisfará las expectativas legítimas de los cónyuges. Por tanto, el Reglamento de régimen económico matrimonial y la consiguiente ley austriaca son aplicables tanto si los cónyuges permanecieron en Austria como si se trasladaron a Alemania. En otras palabras, su traslado a Alemania no influiría en la ley aplicable a su régimen económico matrimonial.

Por otro lado, la alternativa 2 puede resultar menos satisfactoria para las expectativas de Peter y Michael. La Constitución croata ${ }^{49}$ y la Ley de la Familia ${ }^{50}$ limita el matrimonio a las parejas del sexo opuesto. Las parejas del mismo sexo pueden, en cambio, celebrar una unión civil. ${ }^{51}$ Como ya se ha mencionado anteriormente, el legislador croata también se anticipó a los problemas relativos a la caracterización del matrimonio entre personas del mismo sexo y abordó esta cuestión en el artículo 32, apartado 2, del ZMPP, que establece que los matrimonios entre personas del mismo sexo celebrados en el extranjero serán reconocidos como uniones civiles. De conformidad con el artículo 40, apartado 3, del ZMPP, la ley aplicable a las consecuencias patrimoniales de las uniones civiles se determinará de acuerdo con el Reglamento sobre las consecuencias patrimoniales de las uniones registradas. Esto nos lleva a la conclusión de que lo más probable es que los tribunales croatas "rebajen" el matrimonio de Peter y Michael y lo traten como una pareja registrada. La ley aplicable a su régimen patrimonial se determinará, por tanto, de conformidad con el artículo 26, apartado 1, del Reglamento sobre los efectos patrimoniales de las uniones registradas, que señala la ley del Estado bajo cuya legislación se creó la unión registrada. En el presente caso, se trata de la ley alemana. De la alternativa 2 se desprende que el traslado de los cónyuges a Croacia provocó el cambio de la ley aplicable a su régimen patrimonial. Sin embargo, esto podría no coincidir con las expectativas de

46 A. DUTTA, above n. 27, p. 152.

47 Einführungsgesetz zum Bürgerlichen Gesetzbuche in der Fassung der Bekanntmachung vom 21. September 1994 (BGBl. I S. 2494; 1997 I S. 1061), das zuletzt durch Artikel 2 des Gesetzes vom 4. Mai 2021 (BGB1. I S. 882) geändert worden ist.

48 Véase también: M. ANDRAE, above n. 22, p. 241.

49 Ustav Republike Hrvatske, NN $\underline{56 / 90}, \underline{135 / 97}, \underline{08 / 98}, \underline{113 / 00}, \underline{124 / 00}, \underline{28 / 01}, \underline{41 / 01}, \underline{55 / 01}, \underline{76 / 10}, \underline{85 / 10}, \underline{05 / 14}$; Article 62(2).

50 Obiteljski zakon, NN 103/15, $\underline{\text { 98/19, }}$, Article 12.

51 Zakon o životnom partnerstvu osoba istog spola, NN 92/14, 98/19. 
la pareja. En lugar de aplicar el régimen económico matrimonial austriaco de separación de bienes (Gütertrennung), ${ }^{52}$ los cónyuges entrarán en el régimen alemán de propiedad de las ganancias acumuladas (Zugewinngemeinschaft). ${ }^{53} \mathrm{Si}$ los cónyuges se hubieran trasladado en cambio a un Estado miembro participante en el que los matrimonios entre personas del mismo sexo se reconocen y se tratan simplemente como matrimonio, no se habría producido ese cambio de la ley aplicable (como se desprende de la alternativa 1).

A diferencia de Alemania y Croacia, el legislador esloveno (alternativa 3) no previó ninguna disposición en el derecho internacional privado interno que abordara la caracterización o el reconocimiento de los matrimonios del mismo sexo. Para determinar cuál de los Reglamentos gemelos será aplicable, los tribunales tendrán que interpretar el considerando 17. Si el tribunal considera que la referencia al "derecho nacional" en el considerando 17 debe entenderse como una referencia al derecho sustantivo del Estado miembro, a cuyos tribunales se acudió, rechazará la aplicación del Reglamento sobre los bienes matrimoniales. Al igual que Croacia, la legislación eslovena no contempla los matrimonios entre personas del mismo sexo. ${ }^{54}$ En cambio, permite a las parejas del mismo sexo celebrar una unión civil..$^{55}$ En este caso, el tribunal podría "rebajar" el matrimonio entre personas del mismo sexo a una pareja registrada y aplicar el Reglamento sobre las consecuencias patrimoniales de las parejas registradas. Por otro lado, si la referencia al derecho nacional se entiende como una referencia a una definición o concepto de matrimonio según el derecho internacional privado nacional, una opinión que también apoya el autor de este capítulo, el tribunal esloveno podría llegar a la conclusión de que dicho matrimonio puede calificarse de matrimonio y, por tanto, aplicar el Reglamento sobre los bienes matrimoniales.

La Ley eslovena de Derecho Internacional Privado y de Procedimiento (Zakon o mednarodnem zasebnem pravu in postopku, hereinafter $Z M Z P P)^{56}$ no incluye ninguna disposición explícita que regule el reconocimiento de un matrimonio extranjero (o incluso del matrimonio entre personas del mismo sexo). En el artículo 34 establece que los requisitos para la celebración del matrimonio se regirán para cada persona por la ley del Estado de su nacionalidad en el momento de la celebración del matrimonio. La forma de celebración, en cambio, se rige por la ley del Estado donde se celebró el matrimonio (artículo 35 del ZMZPP). Aunque las bases de datos disponibles sobre la práctica judicial muestran que los tribunales eslovenos aún no se han pronunciado sobre el reconocimiento de los matrimonios entre personas del mismo sexo, puede afirmarse que el matrimonio en cuestión puede ser reconocido. Las disposiciones mencionadas del ZMZPP son neutrales en cuanto al género. También es poco probable que los tribunales sostengan que dicho reconocimiento sea contrario al orden público esloveno. ${ }^{57}$ Además, puede observarse que nuestros cónyuges, que

52 Allgemeine bürgerliches Gesetzbuch, Article 1237; see also: T. PERTOT, 'Austria' in L. RUGGERI, I. KUNDA, S. WINKLER (eds), Family Property and Succession in EU Member States: National Reports on the Collected Data, University of Rijeka, Faculty of Law, Rijeka, 2019, p. 7.

53 Lebenspartnershaftgesetz, Article 6; Bürgerliche Gesetzbuch, Article 1363; see also: T. PERTOT, 'Germany' in L. RUGGERI, I. KUNDA, S. WINKLER (eds), Family Property and Succession in EU Member States: National Reports on the Collected Data, University of Rijeka, Faculty of Law, Rijeka, 2019, p. 267.

54 Družinski zakonik, Official Gazette of Republic of Slovenia, no. 15/17, 21/18 - ZNOrg, 22/19, 67/19 - ZMatR-C in 200/20 - ZOOMTVI), Article 3.

55 Zakon o partnerski zvezi, Official Gazette of Republic of Slovenia, no. $\underline{33 / 16}$, Article 2

56 Uradni list RS, št. 56/99, $\underline{45 / 08}$ - ZArbit in $\underline{31 / 21}$ - odl. US.

57 La ley eslovena de uniones civiles estipula que la unión civil produce los mismos efectos que el matrimonio en todos los ámbitos legales (aparte de la adopción y la fecundación con asistencia biomédica). (aparte de la adopción 
son ciudadanos de Alemania y Dinamarca, donde es posible el matrimonio entre personas del mismo sexo, cumplen los requisitos exigidos por la ley de su nacionalidad. Sobre la base de estas consideraciones, el matrimonio en cuestión podría ser catalogado como matrimonio a efectos del procedimiento de régimen económico matrimonial.

La interpretación del considerando 17 por parte de los tribunales eslovenos será decisiva para responder a la cuestión de cuál de los Reglamentos gemelos debe aplicarse. Esta decisión, como ya se ha demostrado anteriormente, también influirá en la ley aplicable en el presente caso. En el caso de "rebajar" el matrimonio entre personas del mismo sexo, los tribunales aplicarán la ley alemana, ya que se trata de la ley del Estado bajo cuya legislación se creó la unión registrada (artículo 26, apartado 1, del Reglamento sobre las consecuencias patrimoniales de las uniones registradas). Por otro lado, si tratan el matrimonio entre personas del mismo sexo como matrimonio, la ley aplicable será la austriaca, ya que es la ley del Estado de la primera residencia habitual común de los cónyuges tras la celebración del matrimonio (artículo 26(1)(a) del Reglamento sobre el régimen económico matrimonial).

El ejemplo demuestra cómo la falta de una definición autónoma del matrimonio y, en consecuencia, la falta de una delimitación autónoma entre los Reglamentos gemelos afecta a los cónyuges del mismo sexo. Teniendo en cuenta que uno de los objetivos centrales de los Reglamentos gemelos era proporcionar seguridad jurídica y cierto grado de previsibilidad, ${ }^{58}$ se puede concluir que estos objetivos sólo se han alcanzado en parte. Como se ha demostrado anteriormente, un traslado a otro Estado miembro participante puede provocar un cambio de la ley aplicable al régimen económico matrimonial de los cónyuges del mismo sexo. Esto es contrario a los objetivos expresados en el considerando 46 del Reglamento sobre el régimen económico matrimonial y también puede frustrar la libertad de circulación, otro objetivo de los Reglamentos gemelos. Por último, la desigualdad de trato de los cónyuges del mismo sexo, provocada por la falta de una definición autónoma del matrimonio, también podría considerarse contraria al principio de no discriminación consagrado en el artículo 21 de la Carta de los Derechos Fundamentales de la Unión Europea (en lo sucesivo, la Carta). ${ }^{59}$

Para mitigar estos problemas y garantizar una aplicación armonizada de los Reglamentos gemelos, Dutta sugirió otro enfoque. En lugar de caracterizar el matrimonio entre personas del mismo sexo de acuerdo con la lex fori, la referencia al derecho nacional de los Estados miembros en el considerando 17 también puede interpretarse como una referencia al derecho del Estado miembro en el que se celebró el matrimonio (lex loci celebrationis). ${ }^{60}$ Este enfoque puede mejorar la previsibilidad jurídica para los cónyuges

y la fecundación con asistencia biomédica). Las consecuencias patrimoniales de una unión civil (del mismo sexo) son, por tanto, idénticas a las del matrimonio. Además, al interpretar el

concepto de orden público, el Tribunal Supremo esloveno ya dictaminó que el reconocimiento de una decisión extranjera extranjera que permite la adopción de un niño por parte de cónyuges del mismo sexo no es contraria al orden público esloveno el orden público esloveno (Decisión II Ips 462/2009, 28. 1. 2010). Aunque esta decisión se dictó en circunstancias fácticas diferentes, no obstante, indica la opinión del Tribunal Supremo sobre las limitaciones a la interpretación del orden público.

58 Véase inter alia Recitals no. 15, 43, 46 and 72 of the Matrimonial Property Regulation and Recitals no. 15, 42, 45 and 70 of the Regulation on the Property Consequences of Registered Partnerships.

59 C 326/391, 26. 10. 2012.

60 A. DUTTA, above n. 27, p. 149. 
del mismo sexo. En otras palabras, permitiría a los Estados miembros participantes, cuya legislación nacional no permite los matrimonios entre personas del mismo sexo, aplicar no obstante el Reglamento sobre los bienes matrimoniales. De este modo, se podría lograr una delimitación más uniforme entre los ámbitos de aplicación de los Reglamentos gemelos. Sin embargo, esta interpretación -aunque potencialmente deseable para los cónyuges del mismo sexo- es menos probable. ${ }^{61}$ El considerando 17 menciona el derecho nacional de los Estados miembros. Si los cónyuges hubieran contraído matrimonio en un Estado miembro no participante o en un tercer Estado, esta caracterización no sería posible. También es poco probable que el Estado miembro, donde ya se intentó resolver el problema de la caracterización en sus normas de conflicto de leyes, recurra a este enfoque.

\section{JURISDICCIÓN ALTERNATIVA}

La omisión de la definición de matrimonio no fue el único intento de responder a las preocupaciones de los Estados miembros "conservadores". En el artículo 9, el Reglamento sobre los regímenes económicos matrimoniales prevé una "jurisdicción alternativa". Esta disposición, considerada por algunos como la más original del Reglamento, ${ }^{62}$ permite al tribunal competente en virtud de los artículos 4, 6, 7 u 8 declinar excepcionalmente su competencia si considera que, en virtud de su Derecho internacional privado, el matrimonio en cuestión no está reconocido a efectos del procedimiento de régimen económico matrimonial. Los tribunales que deseen declinar su competencia deberán hacerlo sin demora injustificada.

Como ya se ha indicado anteriormente, esta disposición responde a las formas divergentes en que los Estados miembros regulan las uniones entre personas del mismo sexo e intenta tranquilizar a aquellos Estados miembros que limitan el matrimonio a las parejas de distinto sexo, de que no se verán obligados a reconocer formas de unión desconocidas para su sistema jurídico y potencialmente contrarias a su política pública. ${ }^{63} \mathrm{~A}$ menudo se establece un paralelismo entre el artículo 9 del Reglamento sobre el régimen económico matrimonial y el artículo 13 del Reglamento Roma III ${ }^{64} .{ }^{65}$ Este último estipula, entre otras cosas, que los tribunales de los Estados miembros participantes no están obligados a pronunciar el divorcio en virtud del Reglamento Roma III si su ley no considera válido el matrimonio en cuestión a efectos del procedimiento de divorcio. Aunque el artículo 9 se refiere a la competencia internacional y el artículo 13 a la ley aplicable, puede observarse que ambos tienen una finalidad similar y se incluyeron para facilitar la unanimidad entre los Estados miembros.

Si los órganos jurisdiccionales de un Estado miembro participante se acogen a la posibilidad prevista en el artículo 9 del Reglamento de régimen económico matrimonial

61 Véase taambién: I. KUNDA, above n. 30, p. 29.

62 P. FRANZINA, 'Article 9: Alternative Jurisdiction' in P. FRANZINA and I. VIARENGO, The EU Regulations on the Property Regimes of International Couples: A Commentary, Edwad Elgar Publishing, Cheltenham, 2020, p. 104; S. MARINO, above n. 32, p. 276.

63 P. FRANZINA, above n. 61, p. 104-105.

64 Reglamento (UE) n. ${ }^{\circ}$ 1259/2010 del Consejo, de 20 de diciembre de 2010, por el que se aplica una cooperación reforzada en el ámbito de la ley aplicable al divorcio y a la separación judicial, DO L 343/10.

65 P. FRANZINA, above n. 61, p. 105. 
y declinan la competencia, los cónyuges podrían presentar su caso ante los órganos jurisdiccionales de otros Estados miembros participantes. El apartado 2 del artículo 9 les ofrece varias posibilidades. Pueden designar los órganos jurisdiccionales competentes celebrando un acuerdo de elección de foro de conformidad con el artículo 7, o pueden acudir a los órganos jurisdiccionales de otro Estado miembro participante de conformidad con el artículo 6 (Competencia en otros casos) o el artículo 8 (Competencia basada en la comparecencia del demandado). También pueden recurrir a los tribunales del Estado miembro en el que se celebró el matrimonio.

Se argumenta que el artículo 9 tiene importantes consecuencias prácticas para los cónyuges del mismo sexo, ya que evita el riesgo de que un tribunal, al decidir sobre el fondo del asunto, declare que su matrimonio no produce consecuencias patrimoniales. ${ }^{66}$ Tal decisión sobre el fondo produciría efectos de res iudicata y podría obstaculizar la posibilidad de que los cónyuges lleguen a una decisión sobre sus bienes matrimoniales en los demás Estados miembros. ${ }^{67}$ Por lo tanto, la denegación de la vista, tal como se regula en el artículo 9, sería preferible para los cónyuges.

Sin embargo, la inclusión del artículo 9 plantea otra cuestión. Si las referencias al derecho nacional en el considerando 17 se entendieran efectivamente como una referencia al derecho sustantivo del forum, entonces el artículo 9 tendría poco valor práctico. ${ }^{68}$ Los Estados miembros que limitan el matrimonio a los cónyuges del sexo opuesto se negarían a calificar el matrimonio entre personas del mismo sexo como matrimonio y, por lo tanto, rechazarían la aplicación del Reglamento sobre los bienes matrimoniales (y su artículo 9). Esto corrobora aún más la opinión de que el considerando 17 debe entenderse como una referencia a la definición de matrimonio según el Derecho internacional privado del forum.

\section{LA AUTONOMÍA DE LOS PARTIDOS: ¿UNA POSIBLE SOLUCIÓN A LA INCERTIDUMBRE?}

Con el objetivo de aumentar la previsibilidad y la seguridad jurídica de las parejas transfronterizas, los Reglamentos gemelos les permiten ejercer la autonomía de la voluntad. ${ }^{69}$ Tanto los cónyuges como las parejas de hecho registradas pueden celebrar acuerdos de elección de foro y de ley. Esta solución puede parecer especialmente atractiva para los cónyuges del mismo sexo, que desean evitar parte de la incertidumbre derivada de la aceptación divergente de los matrimonios del mismo sexo entre los Estados miembros. Si bien la celebración de tales acuerdos puede resultar útil en determinadas circunstancias, un examen más detallado muestra que el sistema de autonomía de las partes establecido en los Reglamentos gemelos tiene varias limitaciones, por lo que la autonomía de las partes debe ejercerse con precaución y con conocimiento de los posibles problemas.

66 S. MARINO, above n. 31, p. 276.

67 Ibid.

68 Véase también: P. FRANZINA, above n. 61, p. 105 - 106. See also: A. DUTTA, above n. 27, p. 151; M. ANDRAE, above n. 22 , p. 285 .

69 Véase: Los considerandos no. 36, 45 y 46 del Reglamento sobre el régimen económico matrimonial y los considerandos $\mathrm{n}^{\circ} .37,44$ y 45 del Reglamento sobre las consecuencias patrimoniales de las uniones registradas. 


\subsection{Acuerdo de elección de foro}

De acuerdo con el artículo 7 de los Reglamentos gemelos, si no es posible la aplicación de los artículos 4 y 5 y la consiguiente concentración de competencias, ${ }^{70}$ los cónyuges y la pareja pueden acordar que los tribunales del Estado miembro elegido sean los únicos competentes para decidir sobre sus relaciones patrimoniales. Estos acuerdos de elección de foro pueden celebrarse antes o después de la celebración del matrimonio (o del registro de la pareja). ${ }^{71}$ Pueden formar parte de un acuerdo matrimonial más amplio o estar relacionados con un acuerdo de elección de ley o incluso celebrarse por separado. ${ }^{72}$

La celebración de un acuerdo de elección de foro parece ser una herramienta útil, especialmente para los cónyuges del mismo sexo. En primer lugar, al designar los tribunales competentes, los cónyuges del mismo sexo pueden evitar la jurisdicción de los tribunales de un Estado miembro en el que es probable que su matrimonio sea "degradado" a una unión registrada. En segundo lugar, esto también puede evitar la posibilidad de que el tribunal competente rechace la aplicación de una disposición de la ley designada basándose en su orden público, como se estipula en el artículo 31 de los Reglamentos gemelos.

Según los Reglamentos gemelos, los cónyuges o las parejas registradas sólo pueden elegir los tribunales de los 18 Estados miembros participantes. ${ }^{73}$ De conformidad con el artículo 7 del Reglamento sobre el régimen económico matrimonial, los cónyuges tienen además cuatro posibilidades. Pueden elegir los órganos jurisdiccionales del Estado miembro cuya ley sea aplicable en virtud de un acuerdo de elección de ley (artículo 22 del Reglamento sobre los bienes matrimoniales). Si los cónyuges no han llegado a un acuerdo sobre la ley aplicable, también pueden elegir los órganos jurisdiccionales del Estado miembro cuya ley sea aplicable en virtud del artículo 26, apartado 1, letra a), o del artículo 26, apartado 1, letra b), es decir, los órganos jurisdiccionales de los Estados miembros de la primera residencia habitual común de los cónyuges tras la celebración del matrimonio o de la nacionalidad común de los cónyuges en el momento de la celebración del matrimonio. Por último, los cónyuges también pueden elegir los tribunales de los Estados miembros de la celebración del matrimonio. Como explica el considerando 37, este último es el Estado miembro ante cuyas autoridades se celebra el matrimonio. Para los cónyuges del mismo sexo, la posibilidad de elegir los órganos jurisdiccionales del Estado miembro de celebración del matrimonio reviste especial importancia, ya que les garantiza que la decisión sobre su régimen económico matrimonial será adoptada por un órgano jurisdiccional que reconocerá su matrimonio. Las parejas registradas, en cambio, sólo pueden elegir entre dos posibilidades. Pueden acordar la competencia exclusiva de los tribunales del Estado miembro cuya ley sea aplicable en virtud de un acuerdo de elección de la ley (artículo 22 del Reglamento sobre los efectos patrimoniales de las uniones registradas) o de los tribunales del Estado miembro bajo cuya ley se creó la unión registrada. ${ }^{74}$

70 Véase el capítulo 4 de este volumen para las cuestiones relativas a la jurisdicción internacional.

71 M. ANDRAE, above n. 22, p. 275.

72 Ibid., p. 276.

73 En general, los cónyuges también pueden elegir los tribunales de los Estados miembros no participantes o de terceros Estados. No obstante, estos acuerdos se regirán por el Derecho internacional privado nacional del Estado elegido y no por el Reglamento del Mellizo. Estado elegido y no por los Reglamentos gemelos.

74 El artículo 7 del Reglamento sobre las consecuencias patrimoniales de las uniones registradas también estipula que las parejas registradas pueden elegir el tribunal del Estado miembro cuya ley sea aplicable en virtud del artículo 
Al celebrar un acuerdo de elección de foro, los cónyuges y las parejas registradas también deben observar los requisitos de validez formal, que se estipulan en el artículo 7, apartado 2, de los Reglamentos gemelos. Su acuerdo debe ser "expresado por escrito, fechado y firmado por las partes". Las comunicaciones por medios electrónicos que proporcionan un registro duradero del acuerdo también se consideran equivalentes a la forma escrita. Si bien la validez formal se regula expresamente en el Reglamento de Gemelos, no se incluye ninguna disposición relativa a la validez material. Por lo tanto, ésta debe determinarse de acuerdo con la legislación del Estado miembro cuyos tribunales se hayan elegido. ${ }^{75}$

Es importante señalar que el apartado 1 del artículo 7 establece que las partes pueden determinar qué tribunales serán exclusivamente competentes. El término "partes" debe interpretarse de forma autónoma ${ }^{76} \mathrm{y}$ puede incluir, además de los cónyuges o las parejas registradas, a terceros como los acreedores de la pareja. No obstante, estos terceros solo estarán vinculados por el acuerdo de elección de ley celebrado entre los cónyuges si también lo aceptan. ${ }^{77}$ Los cónyuges del mismo sexo que celebraron un acuerdo de elección de foro y desean evitar la posibilidad de que su matrimonio sea "degradado" pueden seguir incurriendo en ese riesgo si el tercero, que no está vinculado por su acuerdo, recurre al tribunal del Estado miembro donde no se reconocen los matrimonios del mismo sexo.

Otra imprevisibilidad se deriva del hecho de que, de conformidad con el artículo 7 del Reglamento sobre el régimen económico matrimonial, el acuerdo de elección de foro sólo es posible "en los casos contemplados en el artículo 6" (Competencia en otros casos). Esto significa que los cónyuges no pueden sustraerse a la competencia del artículo 4 (Competencia en caso de fallecimiento de uno de los cónyuges) y del artículo 5 (Competencia en caso de divorcio, separación judicial o nulidad del matrimonio). Estos dos artículos tienen por objeto lograr la concentración entre procedimientos conexos y, por lo tanto, conceder la competencia para decidir sobre las cuestiones de régimen matrimonial a los tribunales de los Estados miembros participantes, a los que se recurrió en materia de sucesión y divorcio, separación judicial o nulidad del matrimonio. En la práctica, las cuestiones de régimen económico matrimonial suelen surgir en relación con el fallecimiento de uno de los cónyuges o con el divorcio. Por lo tanto, cabe esperar que la competencia en virtud del Reglamento sobre el régimen económico matrimonial se determine normalmente sobre la base de estos dos artículos. El artículo 6, por otra parte, se aplicará probablemente con menos frecuencia y presentará la base de la jurisdicción en otros casos, como en las disputas entre los cónyuges, si ciertos bienes pertenecen a los bienes comunes de los cónyuges o forman parte de los bienes de separación de uno de ellos. ${ }^{78}$ Para ver cómo se aplica esto en la práctica, consideremos el siguiente ejemplo:

María (ciudadana española) y Judith (ciudadana austriaca) contrajeron matrimonio el 15 de marzo de 2019 en España, país en el que residían en ese momento y en el

26(1). De conformidad con el apartado 1 del artículo 26, se trata de los tribunales del Estado miembro bajo cuya ley se creó la unión registrada. Así pues, este factor de conexión aparece dos veces en el artículo 7.

75 P. FRANZINA and I. VIARENGO, 'Article 7' in P. FRANZINA and I. VIARENGO, The EU Regulations on the Property Regimes of International Couples: A Commentary, Edwad Elgar Publishing, Cheltenham, 2020, p. 90; M. ANDRAE, above n. 22, p. 278.

76 U. BERGQUIST, D. DAMASCELLI, R. FRIMSTON, P. LAGARDE and B. REINHARTZ, The EU Regulations on Matrimonial and Patrimonial Property, Oxford University Press, Oxford 2019, p. 63.

77 M. ANDRAE, above n. 22, p. 276.

78 P. FRANZINA and I. VIARENGO, above n. 74, p. 79. 
que siguen viviendo y trabajando. El 15 de marzo de 2019, los cónyuges también celebraron un acuerdo de elección de foro de conformidad con el artículo 7 del Reglamento sobre el régimen económico matrimonial que atribuía la competencia exclusiva para decidir sobre su régimen económico matrimonial a los tribunales españoles. En marzo de 2020 ambos cónyuges se trasladaron a Eslovenia, donde María falleció el 30 de mayo de 2021. Tras su fallecimiento, surgió un desacuerdo entre Judith y la madre de María en relación con las partes del apartamento de los cónyuges en Liubliana.

El ejemplo plantea, en primer lugar, las cuestiones relativas a la competencia internacional y a la ley aplicable en materia de sucesiones. Ambas cuestiones se regulan en el Reglamento de sucesiones. ${ }^{79}$ En el presente caso, la competencia corresponderá a los tribunales eslovenos, que deberán aplicar la ley eslovena, ya que Eslovenia es el Estado miembro en el que la difunta tenía su residencia habitual en el momento del fallecimiento (artículos 4 y 21 del Reglamento sobre sucesiones). Sin embargo, en el contexto de la sucesión, se ha planteado una cuestión conexa relativa a los bienes matrimoniales. De conformidad con el artículo 4 de los Reglamentos gemelos, el tribunal de un Estado miembro participante, al que se haya recurrido en materia de sucesión de un cónyuge o de una pareja registrada en virtud del Reglamento de sucesiones, también será competente para pronunciarse sobre las cuestiones del régimen económico matrimonial (o las cuestiones de los efectos patrimoniales de la pareja registrada) que se planteen en relación con ese caso de sucesión. Por lo tanto, a pesar del acuerdo de elección de foro entre los cónyuges, los tribunales eslovenos también serán competentes para decidir sobre el litigio relativo a las participaciones en el patrimonio matrimonial de los cónyuges. El hecho de que se haya celebrado un acuerdo de elección de foro no excluirá la competencia de los tribunales eslovenos, ya que se basará en el artículo 4. Además, también puede observarse que las partes implicadas en el litigio sobre los bienes matrimoniales serán la madre de Judith y María, que no participó en la prórroga de la competencia. Dado que la competencia corresponde a los tribunales eslovenos, éstos tendrán que determinar si aplican el Reglamento sobre el régimen económico matrimonial o si "rebajan" el matrimonio y aplican el Reglamento sobre las consecuencias patrimoniales de las uniones registradas. Por lo tanto, el acuerdo de elección de foro no proporcionó seguridad jurídica adicional a los cónyuges del mismo sexo.

Por otra parte, el artículo 5 del Reglamento sobre el régimen económico matrimonial será menos relevante para los cónyuges del mismo sexo. Estipula que un tribunal de un Estado miembro, al que se le haya sometido la solicitud de divorcio, separación judicial o nulidad matrimonial en virtud del Reglamento de Bruselas II a ${ }^{80}$ también será competente para pronunciarse sobre las cuestiones de régimen económico matrimonial que surjan en relación con dicha solicitud. Dado que es comúnmente aceptado que el Reglamento Bruselas II a excluye a los matrimonios del mismo sexo de su ámbito de apli-

79 Reglamento (UE) nº 650/2012 del Parlamento Europeo y del Consejo, de 4 de julio de 2012, sobre competencia, la ley aplicable, el reconocimiento y la ejecución de las resoluciones y la aceptación y de los documentos públicos en materia de sucesiones y sobre la creación de un certificado sucesorio europeo Certificado de sucesión, L 201/107, de 27. 7. 2012.

80 Reglamento (CE) n ${ }^{\circ}$ 2201/2003 del Consejo, de 27 de noviembre de 2003, relativo a la competencia judicial y al reconocimiento y ejecución de resoluciones judiciales en materia matrimonial y de responsabilidad parental responsabilidad parental, por el que se deroga el Reglamento (CE) no 1347/2000, L 338/1, 23. 12. 2003. 
cación, ${ }^{81}$ es poco probable que las cuestiones relativas al régimen económico matrimonial de los cónyuges del mismo sexo puedan plantearse en relación con una solicitud en virtud del Reglamento Bruselas II a.

Otra cuestión puede surgir en relación con los acuerdos de elección de foro. Como se ha visto anteriormente, el Reglamento de régimen económico matrimonial ofrece a los cónyuges un conjunto más amplio de opciones en comparación con las que ofrece a las parejas registradas el Reglamento sobre los efectos patrimoniales de las uniones registradas. Así, los cónyuges también pueden elegir los tribunales del Estado miembro de su primera residencia habitual común tras la celebración del matrimonio o los tribunales del Estado miembro de su nacionalidad común en el momento de la celebración del matrimonio, dos opciones que no están disponibles para las parejas registradas. Es posible imaginar un caso (aunque probablemente poco frecuente en la práctica), en el que los cónyuges del mismo sexo celebren un acuerdo de elección de foro, que sería válido en virtud del Reglamento sobre el régimen económico matrimonial, pero no en virtud del Reglamento sobre las consecuencias patrimoniales de las uniones registradas. Si uno de los cónyuges decidiera posteriormente hacer caso omiso del acuerdo y recurriera a un tribunal de un Estado miembro que "rebajara" los matrimonios entre personas del mismo sexo y, en consecuencia, aplicara el Reglamento sobre las consecuencias patrimoniales de las uniones registradas a sus relaciones patrimoniales, podría plantearse la cuestión de si dicho acuerdo será aceptado como válido por ese tribunal. En otras palabras, ¿declarará el tribunal competente que no tiene jurisdicción debido a la prórroga, o considerará ese acuerdo como inválido? Este problema se asemeja en cierto modo a otra cuestión, señalada en la literatura científica. A saber, la aplicación de la norma de litispendencia cuando, en relación con el mismo matrimonio, los tribunales de un Estado miembro se verían abocados a aplicar el Reglamento sobre los bienes matrimoniales y los tribunales de otro Estado miembro a aplicar el Reglamento sobre las consecuencias patrimoniales de las uniones registradas. ${ }^{82}$ Por el momento, la solución a esta cuestión sigue abierta.

\subsection{Acuerdos de elección de ley}

Además de los acuerdos de elección de foro, los Reglamentos gemelos también permiten a los cónyuges y a las parejas registradas celebrar acuerdos de elección de ley. Así, pueden designar la ley que se aplicará a todos los bienes que constituyen su patrimonio matrimonial o las consecuencias patrimoniales de su unión registrada, independientemente del lugar en el que se encuentren dichos bienes (artículo 21 de los Reglamentos gemelos). Los cónyuges y las parejas de hecho registradas pueden hacer uso de esta posibilidad incluso antes de que se formalice su relación (artículo 22 de los Reglamentos gemelos).

Esta posibilidad puede resultar especialmente beneficiosa para los cónyuges del mismo sexo. Debido a las divergencias en la regulación del derecho de familia nacional del matrimonio entre personas del mismo sexo, se enfrentan a la posibilidad de que el artículo 26 del Reglamento de régimen económico matrimonial (Ley aplicable a falta de elección por las partes) señale la ley que no permite la celebración del matrimonio entre

81 T. RAUSCHER, 'Brüssel IIa-VO' in T. RAUSCHER (ed), Europäisches Zivilprozess- und Kollisionsrecht EuZPR/ EuIPR, Band IV, Otto Schmidt, Cologne, 2015, p. 47; R. HAUSMANN, above n. 22, p. 9.

82 A. DUTTA, above n. 27, p. 150. 
personas del mismo sexo y, en consecuencia, no regule ninguna consecuencia patrimonial de dichos matrimonios. Esto puede ocurrir, entre otras cosas, cuando los cónyuges establezcan su primera residencia habitual común tras la celebración del matrimonio en dicho estado. Por un lado, se puede argumentar que el tribunal competente podría, no obstante, aplicar la ley de dicho Estado, ya que las disposiciones relativas a los regímenes matrimoniales suelen ser neutrales en cuanto al género. ${ }^{83}$ Sin embargo, para evitar cualquier riesgo, los cónyuges del mismo sexo también pueden celebrar un acuerdo de elección de ley en el que designen como aplicable la ley de un Estado que haya abierto el matrimonio a las parejas del mismo sexo y contemple los efectos patrimoniales de dichos matrimonios. La posibilidad de que la ley aplicable no regule las consecuencias patrimoniales de las uniones registradas se previó, por otra parte, en el Reglamento sobre las consecuencias patrimoniales de las uniones registradas. Por lo tanto, el artículo 26 de este reglamento remite a la ley del Estado bajo cuya ley se creó la pareja registrada, ya que esta ley también regulará las consecuencias patrimoniales de dichas parejas.

Debido al principio de aplicación universal del artículo 20 de los Reglamentos sobre gemelos, las parejas pueden designar como aplicable la ley de un Estado miembro participante o la de cualquier otro Estado. Sin embargo, también al elegir la ley aplicable, las parejas se enfrentan a varias limitaciones. Los cónyuges pueden designar como aplicable la ley del Estado en el que ambos o uno de ellos tenga su residencia habitual en el momento de la celebración del acuerdo o la ley del Estado de la nacionalidad de cualquiera de los cónyuges en el momento de la celebración del acuerdo. No obstante, es aconsejable que los cónyuges del mismo sexo elijan la ley del Estado que permite a las parejas del mismo sexo contraer matrimonio y contempla las consecuencias patrimoniales de dichos matrimonios. Por otro lado, las parejas registradas están limitadas, en primer lugar, por el requisito de que la ley designada tiene que atribuir consecuencias patrimoniales a la institución de la pareja registrada. Este planteamiento es necesario, ya que, a diferencia del matrimonio, sólo varios estados regulan las parejas registradas. Si se cumple esta condición, las parejas registradas pueden elegir entre tres opciones. En primer lugar, pueden designar como aplicable la ley del Estado en el que ambos o uno de ellos tenga su residencia habitual en el momento de la celebración del acuerdo. En segundo lugar, pueden elegir la ley de la nacionalidad de cualquiera de los socios en el momento de la celebración del acuerdo; o en tercer lugar, pueden optar por la ley del estado bajo cuya ley se creó la sociedad registrada.

Los cónyuges y las parejas registradas que celebraron un acuerdo de elección de foro, sin embargo, deben tener cuidado con algunas limitaciones a los efectos de dichos acuerdos. Dado que la ley designada por la pareja también regula los efectos del régimen económico matrimonial (o los efectos patrimoniales de la unión registrada) en una relación jurídica entre un cónyuge (o pareja) y terceros (artículo 27(f) de los Reglamentos gemelos), se prevé una protección especial para los terceros. En virtud del artículo 28 de los Reglamentos gemelos, la ley designada no puede invocarse contra el tercero a menos que éste conozca o deba conocer dicha ley. Además, los efectos retroactivos de un acuerdo de elección de ley (si la pareja decide que el acuerdo debe producir efectos retroactivos) no pueden afectar negativamente a los terceros (artículo 22(3) de los Reglamentos gemelos.

83 A. DUTTA, above n. 27, p. 153; M. ANDRAE, above n. 22, p. 242. 


\section{RECONOCIMIENTO Y EJECUCIÓN}

Una vez que un tribunal se ha pronunciado sobre las relaciones patrimoniales de una pareja del mismo sexo, el reconocimiento y la ejecución de dicha decisión en un Estado extranjero puede presentarse como la última incertidumbre a la que se enfrentará la pareja. La cuestión central que se plantea en relación con las parejas del mismo sexo es la posibilidad de que un tribunal rechace el reconocimiento y la ejecución de una decisión extranjera invocando razones de orden público. El proceso legislativo de los Reglamentos gemelos demuestra que esta cuestión era especialmente problemática para algunos Estados miembros (más conservadores). Como se ha señalado anteriormente, sus reservas se basaban especialmente en el temor de que, en virtud del Reglamento sobre Mellizos, sus tribunales tuvieran que reconocer y ejecutar las resoluciones sobre las relaciones patrimoniales de las parejas del mismo sexo, lo que, en consecuencia, extendería los efectos de dichas relaciones también a su territorio. ${ }^{84}$

Las disposiciones del Capítulo IV de los Reglamentos gemelos, relativas al reconocimiento y la ejecución, se aplicarán únicamente cuando una resolución se haya dictado en un Estado miembro participante y se solicite su reconocimiento y ejecución en otro Estado miembro participante. Puede observarse que las disposiciones del capítulo IV se asemejan y siguen el sistema de reconocimiento y ejecución de otros instrumentos de la UE, como el Reglamento de Bruselas II y el Reglamento de sucesiones antes mencionados, así como el Reglamento de Bruselas ${ }^{85}$ y el Reglamento de Mantenimiento. ${ }^{86}$ Esto es especialmente importante, ya que la práctica judicial del Tribunal de Justicia de la Unión Europea (en adelante, el TJUE) relativa a estos reglamentos puede utilizarse al interpretar el capítulo IV de los Reglamentos gemelos. ${ }^{87}$

De conformidad con el artículo 36 de los Reglamentos gemelos, una resolución extranjera puede ser reconocida sin ningún procedimiento especial (reconocimiento ipso iure). Alternativamente, una resolución también puede ser reconocida en un procedimiento especial o considerada incidentalmente (como cuestión prejudicial). Por otra parte, una resolución extranjera sólo puede ejecutarse en otro Estado miembro si ha sido (a petición de cualquier parte interesada) declarada ejecutiva por los tribunales de dicho Estado (artículo 42 de los Reglamentos gemelos). Los motivos para denegar el reconocimiento y la ejecución se enumeran en el artículo 37, que incluye los cuatro motivos "clásicos" que también se encuentran en otros instrumentos de la UE en el ámbito del Derecho internacional privado. Entre otras cosas, también puede denegarse el reconocimiento y la ejecución de una resolución extranjera si ello fuera manifiestamente contrario al orden público del Estado miembro en el que se solicita el reconocimiento (artículo 37, apartado 1, letra a)). Esto nos lleva a la cuestión de si se puede denegar el reconocimiento y la ejecución de una resolución por motivos de orden público únicamente porque el tribunal de origen

84 A. WYSOCKA-BAR, above n. 9, pp. 193 - 194.

85 Reglamento (CE) no 44/2001 del Consejo, de 22 de diciembre de 2000, relativo a la competencia judicial, el reconocimiento y la de las resoluciones judiciales en materia civil y mercantil [2001] DO 12/1.

86 Reglamento (CE) n ${ }^{\circ} 4 / 2009$ del Consejo, de 18 de diciembre de 2008, relativo a la competencia, la ley aplicable, el reconocimiento y la ejecución de las resoluciones y la cooperación en materia de obligaciones de alimentos [2009]. DO L $7 / 1$.

87 U. BERGQUIST, D. DAMASCELLI, R. FRIMSTON, P. LAGARDE and B. REINHARTZ, above n. 75, pp. $140-141$. 
se haya pronunciado sobre las relaciones patrimoniales de los cónyuges del mismo sexo. Analicemos esta cuestión a través del siguiente ejemplo:

Louis (ciudadano belga) y Mark (ciudadano neerlandés) contrajeron matrimonio en abril de 2019 en Bélgica y se instalaron en Bruselas. Al contraer matrimonio, los cónyuges celebraron un acuerdo matrimonial y optaron por el régimen de separación de bienes. Tras pronunciarse el divorcio en Bélgica en abril de 2021, Mark también tuvo éxito con la demanda de indemnización sobre la base del régimen patrimonial de los cónyuges y solicita la declaración de ejecutabilidad en Bulgaria, donde Louis ha adquirido previamente una villa de vacaciones en la costa del Mar Negro.

En el presente caso, un tribunal de Bulgaria deberá determinar en primer lugar cuál de los Reglamentos gemelos debe aplicarse en el procedimiento de ejecución. Cabe señalar que la legislación búlgara no contempla los matrimonios entre personas del mismo sexo (la Constitución búlgara limita explícitamente el matrimonio a los cónyuges del sexo opuesto) ni las parejas de hecho registradas del mismo sexo. ${ }^{88}$ Debido a la mencionada falta de delimitación autónoma entre sus ámbitos de aplicación personales, es posible que el tribunal búlgaro aplique el Reglamento sobre las consecuencias patrimoniales de las uniones registradas, aunque la sentencia belga se haya dictado con arreglo al Reglamento sobre el régimen matrimonial. ${ }^{89}$ Sin embargo, esto no tiene ninguna consecuencia práctica para los cónyuges, ya que las disposiciones sobre reconocimiento y ejecución son idénticas en ambos reglamentos. También debe observarse que el tribunal búlgaro no puede declinar su competencia en virtud del artículo 9, ya que esto sólo es posible cuando se recurre a un tribunal en virtud de los artículos $4,6,7$ y $8 .{ }^{90}$

Una cuestión más apremiante para el cónyuge sería que el tribunal búlgaro (en la apelación del otro cónyuge) considerara que la ejecución de dicha sentencia es manifiestamente contraria a su orden público. A este respecto, hay que tener en cuenta varias consideraciones. Aunque el orden público es un concepto que se define de forma diferente en cada Estado miembro participante, los tribunales nacionales deben, no obstante, tener en cuenta la jurisprudencia del TJUE, que ha trazado continuamente los límites de su aplicación..$^{91}$ Esta jurisprudencia demuestra que todos los motivos de denegación deben interpretarse de forma estricta, ya que representan un obstáculo a la libre circulación de las sentencias. ${ }^{92}$ Hay que tener especial cuidado con la cláusula de orden público, que sólo debe invocarse en casos excepcionales. ${ }^{93}$ Por lo tanto, el recurso a la cláusula de

88 D. SARBINOVA, 'Bulgaria' in L. RUGGERI, I. KUNDA, S. WINKLER (eds), Family Property and Succession in EU Member States: National Reports on the Collected Data, University of Rijeka, Faculty of Law, Rijeka, 2019, p. 52.

89 Cf. M. ANDRAE, above n. 22, p. 241.

90 Véase también: M. GEBAUER, 'Article 38: Fundamental rights' in P. FRANZINA and I. VIARENGO, The EU Regulations on the Property Regimes of International Couples: A Commentary, Edwad Elgar Publishing, Cheltenham, 2020, pp. 358-359.

91 U. BERGQUIST, D. DAMASCELLI, R. FRIMSTON, P. LAGARDE and B. REINHARTZ, above n. 75, p. 152.

92 Asunto C-414/92, Solo Kleinmotoren GmbH v Emilio Boch, ECLI:EU:C:1994:221; see also: N. POGORELČNIK VOGRINC, 'Refusal of Recognition and Enforcement' in M. CAZORLA GONZALEZ, M. GIOBBI, J. KRAMBERGER ŠKERL, L. RUGERRI and S. WINKLER (eds), Property relations of cross border couples in the European Union, Edizioni Scientifiche Italiane, Naples 2020, p. 148.

93 Asunto C-7/98, Dieter Krombach v André Bamberski, ECLI:EU:C:2000:164; Case C-145/86, Horst Ludwig Martin Hoffmann v Adelheid Krieg, ECLI:EU:C:1988:61. 
orden público sólo debería ser posible cuando el reconocimiento y la ejecución de una resolución extranjera fueran manifiestamente contrarios a los valores fundamentales del Estado, donde se solicita el reconocimiento y la ejecución y causaran efectos jurídicos intolerables en ese ordenamiento jurídico. ${ }^{94}$

Además, el tribunal al que se solicita el reconocimiento y la ejecución también debe considerar las restricciones estipuladas en el artículo 38 de los Reglamentos gemelos. Según su redacción, todos los motivos de denegación se aplicarán "respetando los derechos y principios fundamentales reconocidos en la Carta, en particular en su artículo 21 sobre el principio de no discriminación”. Es la primera vez que un instrumento de la UE en el ámbito del Derecho internacional privado incluye una disposición de este tipo. Anteriormente, estas referencias a la Carta sólo se hacían en los preámbulos ${ }^{95} \mathrm{o}$ se omite por completo. ${ }^{96}$ Este paso del preámbulo a la parte normativa puede entenderse como la intención de reforzar la importancia de la observancia de los derechos fundamentales. ${ }^{97}$ También puede considerarse que intenta reforzar la libre circulación de sentencias entre los Estados miembros participantes.

Aunque los límites de la interpretación de la excepción de orden público deberán ser establecidos por los tribunales de los Estados miembros participantes (y, potencialmente, por el TJUE), las consideraciones anteriores y, en particular, la inclusión del artículo 38, que hace referencia al principio de no discriminación, indican que puede no ser posible una negativa a reconocer o ejecutar una resolución extranjera únicamente por el hecho de que regule las relaciones patrimoniales de una pareja del mismo sexo. El artículo 38 representa, por lo tanto, una novedad bienvenida en el Derecho internacional privado de la UE y proporciona una importante salvaguarda en relación con las parejas del mismo sexo.

\section{OBSERVACIONES FINALES}

La adopción de los Reglamentos gemelos demostró lo difícil que es para la UE encontrar la unanimidad en el ámbito del Derecho de familia europeo y lo polémicas que siguen siendo las relaciones entre personas del mismo sexo en varios Estados miembros. En la búsqueda del mínimo común denominador, la seguridad jurídica de las parejas del mismo sexo (y en particular de los cónyuges del mismo sexo) se sacrificó a menudo en aras de la unanimidad. Con ello, se perdió una importante oportunidad, y los cónyuges del mismo sexo seguirán enfrentándose a la falta de previsibilidad que se ofrece a los cónyuges "tradicionales" del sexo opuesto.

Es especialmente lamentable (aunque comprensible) que se haya evitado una definición europea autónoma del matrimonio en los Reglamentos gemelos. En relación con las parejas del mismo sexo, esta omisión puede considerarse la cuestión central que pro-

94 J. KRAMBERGER ŠKERL, '(Ne)razumevanje pridržka javnega reda in posvojitev s strain istospolnih partnerjev' (2010) no. 29-30 Pravna praksa 26, 26. See also: Case C-507/15, Agro Foreign Trade \& Agency Ltd v Petersime NV, ECLI:EU:C:2017:129.

95 Véase inter alia El considerando núm. 81 del Reglamento 650/2012 y el Considerando nº 33 del Reglamento $2201 / 2003$.

96 Véase, por ejemplo, el Reglamento 4/2009.

97 A. WYSOCKA-BAR, above n. 9, p. 193. 
voca esta falta de previsibilidad. Como se demuestra en este capítulo, este tratamiento de las parejas del mismo sexo no sólo puede contradecir el principio de no discriminación consagrado en el artículo 21 de la Carta, sino que también puede obstaculizar la libre circulación de las parejas del mismo sexo dentro de la UE.

Aunque cabe esperar que el desarrollo de la práctica judicial en los Estados miembros participantes y por parte del TJUE produzca una mayor claridad en cuanto al ámbito de aplicación material y personal de los Reglamentos gemelos, el hecho es que el tratamiento de los cónyuges del mismo sexo seguirá dependiendo de la comprensión nacional de la noción de matrimonio: un problema que, con toda probabilidad, sólo podrá superarse en el futuro mediante una mayor aceptación social y jurídica de las relaciones entre personas del mismo sexo en los Estados miembros y una consiguiente disposición al consenso. 